\title{
RADIATION DAMAGE MEASUREMENTS IN ROOM TEMPERATURE SEMICONDUCTOR RADIATION DETECTORS
} \author{
Larry A. Franks ${ }^{1}$, Bruce A. Brunett ${ }^{1,2}$, Richard W. Olsen ${ }^{1}$, David S.Walsh ${ }^{3}$, Gyögy Viz
Jacob I. Trombka ${ }^{4}$, Barney L. Doyle ${ }^{3}$, and Ralph B. James
}

1. Sandia National Laboratories, Livermore, CA 94550

2. ECE Department, Carnegie Mellon University, Pittsburgh, PA 15213

3. Sandia National Laboratories, Albuquerque, NM 87185

4.NASA Goddard Space Flight Center, Greenbelt, MD 20771

5. Idaho State University, Pocatello, ID 83209

\begin{abstract}
The literature of radiation damage measurements on cadmium zinc telluride (CZT), cadmium telluride (CT), and mercuric iodide $\left(\mathrm{HgI}_{2}\right)$ is reviewed and in the case of CZT supplemented by new alpha particle data. CZT strip detectors exposed to intermediate energy $(1.3 \mathrm{MeV})$ proton fluences exhibit increased interstrip leakage after $10^{10} \mathrm{p} / \mathrm{cm}^{2}$ and significant bulk leakage after $10^{12} \mathrm{p} / \mathrm{cm}^{2}$. CZT exposed to $200 \mathrm{MeV}$ protons shows a two-fold loss in energy resolution after a fluence of $5 \times 10^{9} \mathrm{p} / \mathrm{cm}^{2}$ in thick $(3 \mathrm{~mm})$ planar devices but little effect in $2 \mathrm{~mm}$ devices. No energy resolution effects were noted from moderated fission spectrum of neutrons after fluences up to $10^{10} \mathrm{n} / \mathrm{cm}^{2}$, although activation was evident. Exposures of CZT to $5 \mathrm{MeV}$ alpha particle at fluences up to $1.5 \times 10^{10} \alpha / \mathrm{cm}^{2}$ produced a near linear decrease in peak position with fluence and increases in FWHM beginning at about $7.5 \times 10^{9} \alpha / \mathrm{cm}^{2}$. CT detectors show resolution losses after fluences of $3 \times 10^{9} \mathrm{p} / \mathrm{cm}^{2}$ at $33 \mathrm{MeV}$ for chlorine-doped detectors. Indium doped material may be more resistant. Neutron exposures $(8 \mathrm{MeV})$ caused resolution losses after fluences of $2 \times 10^{10}$ $\mathrm{n} / \mathrm{cm}^{2}$. Mercuric iodide has been studied with intermediate energy protons $(10$ to $33 \mathrm{MeV})$ at fluences up to $10^{12} \mathrm{p} / \mathrm{cm}^{2}$ and with $1.5 \mathrm{GeV}$ protons at fluences up to $1.2 \times 10^{8} \mathrm{p} / \mathrm{cm}^{2}$. Neutron exposures at $8 \mathrm{MeV}$ have been reported at fluences up to $10^{15} \mathrm{n} / \mathrm{cm}^{2}$. No radiation damage was reported under these irradiation conditions.

DISTRIBUTION OF THIS DOCUMENT IS UNLMITED
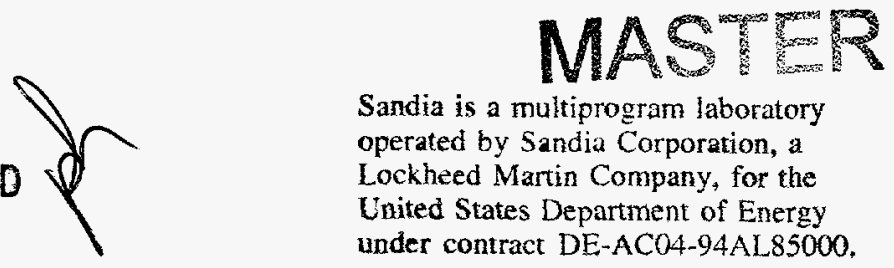

Sandia is a multiprogram laboratory operated by Sandia Corporation, a Lockheed Martin Company, for the United States Department of Energy under contract DE-AC04-94AL85000.
\end{abstract}




\section{Introduction}

The well documented radiation damage in cryogenic germanium and silicon detectors (refs 1,2) at relatively modest charge particle fluences has prompted interest in the response of the room temperature semiconductor materials now under development. Radiation damage in semiconductor detectors causes degradation of energy resolution, increased leakage current, and reduction of the peak position. Depending on the elemental constituents, activation may also occur in the case of neutron exposures. Exposure parameters affecting the response of materials to radiation fields include the fluence level, flux, incident energy, detector bias, and detector temperature. In addition to the base constituents, trace contaminants as well as detector dimension can also affect radiation response.

In the case of cryogenic silicon, significant energy resolution losses occur at about $10^{12} \mathrm{n} / \mathrm{cm}^{2}$ (ref.1) with leakage current and pulse height changes after $5 \times 10^{11}$ protons $/ \mathrm{cm}^{2}$. Planar germanium detectors exhibit significant resolution losses after $10^{9} \mathrm{n} / \mathrm{cm}^{2}$. Coaxial (n-type) are appreciably more resistant to neutrons than p-type (ref 2). Coaxial ( $\mathrm{p}$-type) germanium detectors begin to show resolution losses at about $2 \times 10^{7} \mathrm{p} / \mathrm{cm}^{2}$ while in $\mathrm{n}$-type coaxial (reverse electrodes) detectors; resolution losses appear at about $2 \times 10^{8} \mathrm{p} / \mathrm{cm}^{2}$. Despite the susceptibility of germanium to radiation damage, thermal annealing methods have been developed to mitigate, if not reverse, the symptoms of high fluence exposures.

In this paper we report the results of a survey of radiation damage studies in the room temperature semiconductor materials: cadmium zinc telluride (CZT), cadmium telluride (CT), and mercuric iodide $\left(\mathrm{HgI}_{2}\right)$. Also reported are new $5 \mathrm{MeV}$ alpha particle data on CZT including $\alpha$ response maps showing material inhomogeneities.

\section{Methods}

Survey data were obtained through a literature search using the computer databases INSPEC and CALPLUS together with DOE archives. In all, more than 300 abstracts were reviewed. The review was confined to the materials cadmium zinc telluride, (CZT), cadmium telluride (CT), and mercuric iodide $\left(\mathrm{HgI}_{2}\right)$, the most promising of the wide-band gap materials now under development.

Alpha particle exposures were made with $\mathrm{He}^{2+}$ ions from the Sandia Tandem Van de Graaff. The flux was maintained at $2.8 \times 10^{7} \alpha / \mathrm{cm}^{2}$-sec and measured by means of a scalar connected to the output of the detector under test. The beam spot size was 1 micron in diameter. Exposures were made in vacuum and carried out by scanning the beam over the surface of the detector. This procedure provided both effects data as well as homogeneity maps of the detector surface. Gross positioning was accomplished with an x-y stage; fine adjustments, over a 250 micron by 250 micron area, were made with the accelerator's beam handling system.

\section{Results}




\section{DISCLAMMER}

This report was prepared as an account of work sponsored by an agency of the United States Government. Neither the United States Government nor any agency thereof, nor any of their employees, makes any warranty, express or implied, or assumes any legal liability or responsibility for the accuracy, completeness, or usefulness of any information, apparatus, product, or process disclosed, or represents that its use would not infringe privately owned rights. Reference berein to any specific commercial product, process, or service by trade name, trademark, manufacturer, or otherwise does not necessarily constitute or imply its endorsement, recommendation, or favoring by the United States Government or any agency thereof. The views and opinions of authors expressed herein do not necessarily state or reflect those of the United States Government or any agency thereof. 


\section{DISCLAIMER}

Portions of this document may be illegible in electronic image products. Images are produced from the best available original document. 
The radiation effect reported most frequently was the change in energy resolution, although changes in the leakage current and peak position shifts were sometimes cited. Energy resolution $(\Delta \mathrm{E})$ was determined in most cases by recording the spectrum of a monochromatic photon or alpha particle before and after exposure. Detector energy resolution is reported here in terms of the full width of a given spectral line at its half intensity point (FWHM). In general, neither the detector bias conditions nor the detector temperature were reported. Where available, this information is noted in this report. The results including the recently obtained $\alpha$ particle data are summarized in Tables 1-3.

\section{Mercuric lodide}

The results of this investigation are summarized in Table 1. Proton exposures at 10, 10.7, 33, and $1500 \mathrm{MeV}$ have been reported at fluences ranging from $1.2 \times 10^{8}$ protons $/ \mathrm{cm}^{2}(1500 \mathrm{MeV})$ to $10^{12}$ protons $/ \mathrm{cm}^{2}(10.7 \mathrm{MeV})$. Also reported were $8 \mathrm{MeV}$ neutron exposures at fluences up to $10^{15} \mathrm{n} / \mathrm{cm}^{2}$.

In $10.7 \mathrm{MeV}$ protons exposures, no losses in energy resolution were found in the $5.9 \mathrm{KeV} \mathrm{Mn}$ $\mathrm{K} \alpha$ line in a group of 6 detectors following fluences up to $10^{12} \mathrm{p} / \mathrm{cm}^{2}$ (ref 3). Similar results were reported (ref 4) for a single detector $0.4 \mathrm{~mm}$ thick in $5.5 \mathrm{MeV} \propto$ peaks for $10 \mathrm{MeV}$ protons at fluences up to $10^{10} \mathrm{p} / \mathrm{cm}^{2}$; the relative pulse height decreased by approximately $20 \%$ following exposure of $10^{11} \mathrm{p} / \mathrm{cm}^{2}$, however. No resolution losses were found in a group of 3 detectors from $33 \mathrm{MeV}$ proton exposures in 59.5 and $122 \mathrm{KeV}$ photon peaks following fluences of up to $2.5 \mathrm{x}$ $10^{10} \mathrm{p} / \mathrm{cm}^{2}$ (ref 5).

A group of 4 detectors with an average active area of $6.4 \mathrm{~mm}^{2}$ were exposed to a flux of $10^{5}$ protons at $1.5 \mathrm{GeV}$ (ref 6). The detectors, initially unbiased, exhibited anomalous leakage current after the first exposure of $2 \times 10^{6}$ protons $/ \mathrm{cm}^{2}$. Subsequent exposures were made under bias and the leakage remained stable. No loss in resolution was found in $5.9 \mathrm{KeV}$ photon peaks following exposures up to $1.2 \times 10^{8} \mathrm{p} / \mathrm{cm}^{2}$. Little effect was found in a single $50 \mathrm{~mm}^{2}$ detector (active thickness $.26 \mathrm{~mm}$ ) from $8 \mathrm{MeV}$ neutron exposures in $5.3 \mathrm{MeV} \alpha$ peaks after fluences up to $10^{15}$ $\mathrm{n} / \mathrm{cm}^{2}$ (ref 4 ). No data on effects from high-energy photon exposures were found. 
TABLE 1.

Radiation Damage in $\mathrm{HgI}_{2}$ Room Temperature Semi-Conductor Detectors

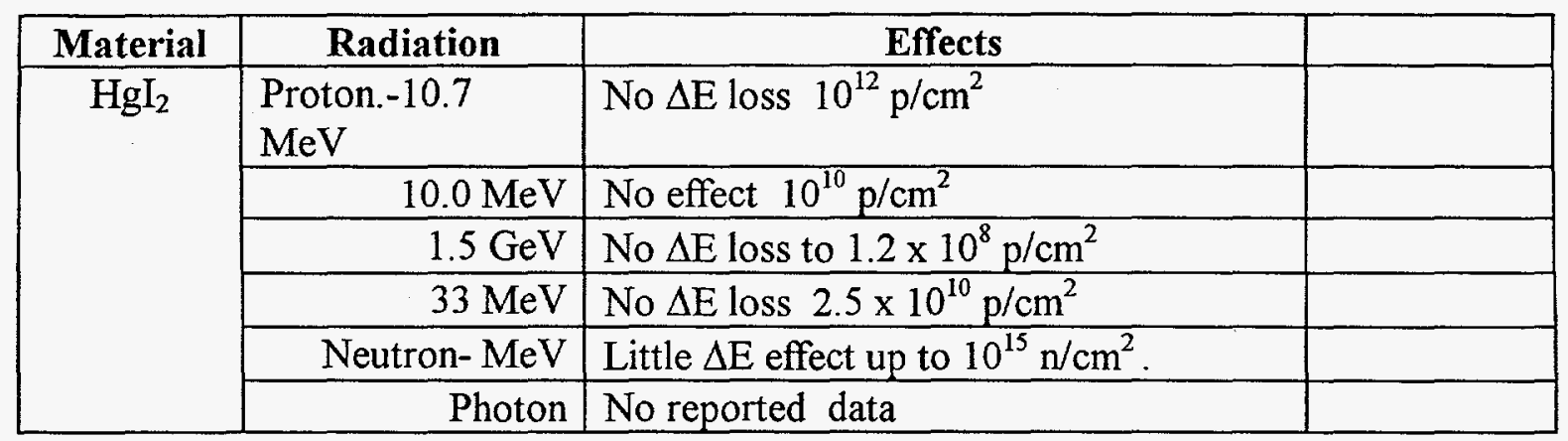

\section{Cadmium Telluride}

Damage studies were found for proton, neutron, and photon irradiation. The results are summarized in Table 2. Proton exposures at $33 \mathrm{MeV}$ were made on chlorine and indium-doped material (ref 5). This energy was selected so that the beam passed through the thickest samples $(2.8 \mathrm{~mm})$ and thus contributed no Bragg peak in the test samples. In chlorine-doped samples, the energy resolution in 59.5 and $122 \mathrm{KeV}$ peaks degraded sharply after about $3 \times 10^{9}$ protons $/ \mathrm{cm}^{2}$. There was some evidence of a slight resolution improvement at lower fluences. Evidence of detector thickness dependence in the resolution response was also noted. While quantitative data were not obtained for the single indium-doped device tested, the data suggests a higher degree of radiation resistance than with the chlorine-doped material. Neutron irradiations were reported at a mean energy of about $3 \mathrm{MeV}$ (ref 7). Significant reductions in energy resolution were reported after about $5 \times 10^{10} \mathrm{n} / \mathrm{cm}^{2}$ in $5.5 \mathrm{MeV}$ alpha spectra using a flux of $10^{8} \mathrm{n} / \mathrm{cm}^{2}-\mathrm{s}$. Photon irradiations were reported using Co-60 (1.17 and $1.33 \mathrm{MeV}$ ) with the resolution monitored at 662 and $59.6 \mathrm{KeV}$ (ref 8). Marked changes in peak shape were reported at both energies after exposure of several times $10^{5} \mathrm{R}$. No data were found at intermediate and low exposure levels. 


\section{TABLE 2.}

Radiation Damage in CdTe Room Temperature Semiconductor Detectors

\begin{tabular}{|c|c|c|}
\hline Material & Radiation/Energy & Effects \\
\hline \multirow[t]{3}{*}{$\mathrm{CdTe}$} & Proton $33 \mathrm{MeV}$ & $\begin{array}{l}\text { Chlorine doped }-\Delta \mathrm{E} \text { degradation after } \\
\sim 3^{3} \times 10^{9} \mathrm{p} / \mathrm{cm}^{2} \\
\text { Indium doped }- \text { evidence of greater } \\
\text { radiation resistance, no quantitative data }\end{array}$ \\
\hline & Neutron $3 \mathrm{MeV}$ & $\begin{array}{l}\text { p-type - increasing } \triangle E \text { loss in } 5.5 \\
\mathrm{MeV} \alpha \text { peaks at } 2 \times 10^{10} \mathrm{n} / \mathrm{cm}^{2}\end{array}$ \\
\hline & $\begin{array}{ll}\text { Photon } 1.25 \\
\mathrm{MeV}\end{array}$ & $\begin{array}{l}\text { Substantial } \Delta \mathrm{E} \text { loss @ } 59.6 \mathrm{KeV} \text { after } \\
10^{5} \mathrm{R}\end{array}$ \\
\hline
\end{tabular}

\section{Cadmium Zinc Telluride}

Radiation damage studies on CZT have been carried out with protons (1.3 and $200 \mathrm{MeV}$ ) and neutrons (moderated fission spectrum). The results of these studies are shown in Table 3. In a single detector with $1.3 \mathrm{MeV}$ protons, the bulk leakage was found to increase significantly after $10^{12} \mathrm{p} / \mathrm{cm}^{2}$ in a single unbiased $10 \times 10 \times 2 \mathrm{~mm}^{3}$ strip detector (ref 9) The interstrip leakage increased significantly after about $10^{10} \mathrm{p} / \mathrm{cm}^{2}$. No energy resolution data were reported.

Considerable work has been reported in the region of $200 \mathrm{MeV}$. In one study (ref 10) 2 and $3 \mathrm{~mm}$ thick planar detectors were irradiated with up to $5 \times 10^{9} \mathrm{p} / \mathrm{cm}^{2}$ and resolution losses were found in the thicker devices $(3 \mathrm{~mm}$ ). The initial (unirradiated) FWHM values at 59.6 and $122 \mathrm{KeV}$ of 3.2 $\mathrm{KeV}$ and $3.9 \mathrm{KeV}$, respectively, degraded to 4.1 and 4.3 after $10^{9} \mathrm{p} / \mathrm{cm}^{2}$ and to 6.2 and $9.2 \mathrm{KeV}$ after $5 \times 10^{9} \mathrm{p} / \mathrm{cm}^{2}$. The thinner device $(2 \mathrm{~mm})$ showed no degradation at either energy after like exposures, however. A downward shift in peak channel with increasing fluence was reported for both thick and thin detectors. The degradation in energy resolution is attributed to radiation induced electron trapping.

In a similar study, (ref 9), both strip and planar detectors were exposed to $200 \mathrm{MeV}$ protons. The strip detectors $\left(15 \times 15 \times 2 \mathrm{~mm}^{3}\right)$ were exposed under bias to fluences from $10^{8}$ to $5 \times 10^{9} \mathrm{p} / \mathrm{cm}^{2}$. A small gain shift (3\%) was noted after a fluence of $1 \times 10^{9} \mathrm{p} / \mathrm{cm}^{2}$ and a significant shift $(>25 \%)$ after $5 \times 10^{9} \mathrm{p} / \mathrm{cm}^{2}$. No consistent pattern of resolution degradation was found. The resolution of a single detector exposed to $5 \times 10^{9} \mathrm{p} / \mathrm{cm}^{2}$ was unchanged at $59.6 \mathrm{KeV}$ but significantly degraded at $122 \mathrm{KeV}$ while small losses (and gains) were found at $1 \times 10^{8}$ and $1 \times 10^{9} \mathrm{p} / \mathrm{cm}^{2}$. In this study, the outputs of three strips in each detector were summed; one detector was used for each fluence level $\left(1,10\right.$, and $\left.50 \times 10^{8} \mathrm{p} / \mathrm{cm}^{2}\right)$. Two planar devices $\left(10 \times 10 \times 2 \mathrm{~mm}^{3}\right.$ and $\left.15 \times 15 \times 2 \mathrm{~mm}^{3}\right)$ were exposed to a fluence of $5 \times 10^{9} \mathrm{p} / \mathrm{cm}^{2}$, one under bias the other unbiased. Gain shift and energy resolution were measured at photon energies of 14.4, 17.8, 59.6, and $122 \mathrm{KeV}$. Gain shifts were found at all energies in both biased and unbiased cases. Significant $(>45 \%)$ resolution 
losses were found at 59.6 and $122 \mathrm{KeV}$ in the unbiased device. Minor changes (both positive and negative) were reported for the biased case.

Neutron irradiation with a moderated fission spectrum source (Cf-252) at fluences up to about $10^{11} \mathrm{n} / \mathrm{cm}^{2}$ have been reported (ref 11) on a single detector. The detector $10 \times 10 \times 2 \mathrm{~mm}^{3}$ was biased during exposure. No resolution degradation was found at photon energies of 14.4, 26.3, 59.6 , and $122 \mathrm{KeV}$ for fluences up to $10^{10} \mathrm{n} / \mathrm{cm}^{2}$. Significant resolution losses were found after $7 \times 10^{10} \mathrm{n} / \mathrm{cm}^{2}$, however. It is interesting to note that the resolution losses were largely recovered after 12 weeks of annealing at room temperature. Evidence of neutron activation, in the form of gamma-ray lines from cadmium and tellurium isotopes, was apparent at fluences beyond about $10^{10} \mathrm{n} / \mathrm{cm}^{2}$. Although not reported, similar effects can be expected in CdTe. 


\section{TABLE 3.}

Radiation Damage in Cadmium Zinc Telluride (CZT) Room Temperature Detectors

\begin{tabular}{|c|c|c|}
\hline Material & Radiation/Energy & Effects \\
\hline \multirow[t]{3}{*}{$\mathrm{CZT}$} & Proton $199 \mathrm{MeV}$ & $\begin{array}{l}\text { onset of } \Delta \mathrm{E} \text { loss at } 10^{8} \mathrm{p} / \mathrm{cm}^{2} ; 2 \\
\text { fold increase in } \Delta \mathrm{E} @ 5 . \times 10^{9} \mathrm{p} / \mathrm{cm}^{2} \\
\text { ( } 3 \mathrm{~mm} \text { thick)thick detector, } \\
\text { little } \Delta \mathrm{E} \text { change in } 2 \mathrm{~mm} \text { device } \\
\text {-- Downward peak shift proportional } \\
\text { to fluence in } 2 \mathrm{~mm} \text { and } 3 \mathrm{~mm} \text { devices }\end{array}$ \\
\hline & Protons $200 \mathrm{MeV}$ & $\begin{array}{l}\text { Strip detector (biased) }>25 \% \text { ) gain } \\
\text { shift following } 5 \times 10^{9} \mathrm{p} / \mathrm{cm}^{2} \\
\frac{\text { Planar }}{\text { (biased)-- Small } \Delta \mathrm{E} \text { effects, both }} \\
\text { positive and negative found @ } 14.4, \\
59.6 \text {, and } 122 \mathrm{KeV} \\
\underline{\text { Planar }} \\
\text { (unbiased) } \\
\text { - Large }(>45 \%) \Delta \mathrm{E} \text { losses following } \\
5 \times 10^{9} \mathrm{p} / \mathrm{cm}^{2} \text { exposure } \\
\text {-- Gain shifts in both biased and } \\
\text { unbiased detectors at } 14.4,17.8,59.6 \text {, } \\
\text { and } 122 \mathrm{KeV}\end{array}$ \\
\hline & Proton $1.3 \mathrm{MeV}$ & $\begin{array}{l}2 \mathrm{~mm} \text { thick strip detector (unbiased) } \\
\text { Bulk leakage increases after } \\
10^{12} \mathrm{p} / \mathrm{cm}^{2} \\
\text { Interstrip leakage increases after } 10^{10} \\
\mathrm{p} / \mathrm{cm}^{2}\end{array}$ \\
\hline
\end{tabular}


TABLE 3. (continued)

Radiation Damage in Cadmium Zinc Telluride (CZT) Room Temperature

Detectors

\begin{tabular}{|c|c|c|}
\hline Material & Radiation/Energy & Effects \\
\hline $\mathrm{CZT}$ & $\begin{array}{l}\text { Neutron Moderated } \\
\text { Fission Spectrum } \\
\text { Alpha } 5 \mathrm{MeV}\end{array}$ & $\begin{array}{l}\text { Planar detection } \\
\text {-- No } \Delta \mathrm{E} \text { effects up to } 10^{10} \mathrm{n} / \mathrm{cm}^{2} \\
\text {-- Measurable } \Delta \mathrm{E} \text { loss @ } 10^{11} \mathrm{n} / \mathrm{cm}^{2} \\
\text {-- Activation emission }(\gamma) \text { at } 10^{10} \\
\mathrm{n} / \mathrm{cm}^{2} \\
\text { linear decrease in peak position with } \\
\text { exposure beginning at } 2.5 \times 10^{9} \alpha / \mathrm{cm}^{2} \\
\Delta \mathrm{E} \text { increases by } 60 \% \text { at } 1.5 \times 10^{10} \\
\alpha / \mathrm{cm}^{2}\end{array}$ \\
\hline
\end{tabular}

The results of this review were supplemented with alpha particle irradiation. The exposures were made with $5 \mathrm{MeV} \mathrm{He}{ }^{2+}$ ions produced in the Sandia Tandem van de Graaff and made on a single $3 \times 3 \times 2 \mathrm{~mm}^{3} \mathrm{CZT}$ detector. The exposures were in vacuum over the region from $2.5 \times 10^{9} \alpha / \mathrm{cm}^{2}$ to $1.5 \times 10^{10} \alpha / \mathrm{cm}^{2}$ by scanning the 1 micron diameter beam spot over the surface of the detector. The flux was maintained at approximately $2.8 \times 10^{7} \alpha / \mathrm{cm}^{2}$-sec by monitoring a scalar connected to the output of the detector. Alpha particle spectra obtained by integrating the pulses from a small irradiated area are shown in Figure 1. Plots of the resultant FWHM and the peak position are shown in figure 2. The data of Figure 2 show a near linear decrease in the peak position with fluence. The FWHM, after decreasing initially, increases by more than $60 \%$ after an exposure of $1.5 \times 10^{10} \alpha / \mathrm{cm}^{2}$. Variation in the response of the detector as measured by the $\alpha$ counts recorded as the detector was scanned are shown in figure 3 . One notes a number of non-responding elements distributed through the sample including a band in the lower left. The cause of this effect is currently under investigation. 


\section{Summary And Conclusions}

Knowledge of the radiation susceptibility of the leading room temperature semiconductor detectors CZT, CdTe, and $\mathrm{HgI}_{2}$, is incomplete. Factors known to be of significance in semiconductor radiation damage such as rate effects (flux), incident energy, and device temperature have not yet been fully examined. Moreover, the available data are from a very small sampling of detectors (sometimes a single device) and do not, in general, cover the complete fluence range of interest.

Despite these shortcomings, several interesting features emerge from the existing data. The most apparent is that $\mathrm{HgI}_{2}$ appears to be relatively immune to proton and neutron-induced radiation damage. No resolution degradation was found from intermediate energy protons at fluences up to $10^{12} \mathrm{p} / \mathrm{cm}^{2}$. Similarly, no degradation was found from high-energy protons although the effects of fluences significantly beyond $10^{8} \mathrm{p} / \mathrm{cm}^{2}$ have not been investigated and accordingly the suitability of $\mathrm{HgI}_{2}$ for long-term space mission remains in question. Additionally, the material is apparently not susceptible to damage from intermediate energy neutrons.

The situation for cadmium telluride is less clear. No data were found for effects of high-energy protons although the results at intermediate energy suggest vulnerability beginning in the region of $10^{8} \mathrm{p} / \mathrm{cm}^{2}$. Neutron data are also incomplete although at intermediate energies $(8 \mathrm{MeV})$ the damage threshold for resolution degradation is relatively high $\left(10^{10} \mathrm{n} / \mathrm{cm}^{2}\right)$. While no evidence of activation was reported, effects similar to those in CZT can be expected.

The radiation susceptibility of CZT is also in question. There is evidence of resolution degradation from $200 \mathrm{MeV}$ protons beginning in the region of $10^{9} \mathrm{p} / \mathrm{cm}^{2}$ as well as a downward shift in peak channel proportional to the proton fluence. However, the resolution degradation was apparent only in a $3 \mathrm{~mm}$ thick device and not a $2 \mathrm{~mm}$ detector. There is also evidence that the resolution degradation is dependent on bias conditions although this is based on the results from a single detector. Detector response changes following high-energy proton irradiation are consistent with increased electron trapping and the associated decreases in the mobility-lifetime product. With intermediate energy protons $(1.3 \mathrm{MeV})$, bulk and interstrip leakage was evident but only at high fluence levels. Damage for moderated fission neutrons is evident only after $10^{10}$ $\mathrm{n} / \mathrm{cm}^{2}$. Neutron activation lines from cadmium and tellurium isotopes appear after about $10^{10} \mathrm{n} / \mathrm{cm}^{2}$. It is interesting to note that annealing at room temperature was very effective in restoring resolution losses. Resolution degradation and the downward trend in peak position from $5 \mathrm{MeV} \alpha$ particles, while based on single detector, are generally consistent with proton data. 


\section{References}

1. G. T. Ewan, Nuclear Instruments and Methods, 162, 75, 1979.

2. R. H. Pehl, N. W. Madden, J. H. Elliott, T. W. Raudorf, R. C. Tramell, and L. S. Darken, IEEE Transactions on Nuclear Science, NS-26, No. 1, p. 321, 1979.

3. J. S. Iwanczyk, Y. J. Young, J. G. Bradley, J. M. Conley, A. L. Albee, and T. E. Economov, IEEE Transactions on Nuclear Science, Vol. 36, No. 1, p. 841, 1989.

4. F. D. Becchetti, R. S. Raymond, R. A. Ristinen, W. F. Schepple, and C. Ortale, Nuclear Instruments and Methods, 213, p. 127, 1983.

6. B. E. Patt, R. C. Dolin, T. M. Devore, J. M. Markakis, J. S. Iwanczyk, N. Dorri, and J. Trombka, Nuclear Instruments and Methods, A 299, p. 176, 1990.

5. G. H. Nakano, W. L. Imhof, and J. R. Kilner, IEEE Transactions Nuclear Science, Vol. NS23, No. 1, p. 468, 1976.

7. R. A. Ristinen, R. J. Petersen, J. J. Hamill, F. D. Becchetti, and G. Entine, Nuclear Instruments and Methods, 188, p. 445, 1981.

8. T. Shoji, T. Taguchi, Y. Hiratate, and Y. Inuishi, IEEE Transactions on Nuclear Science, Vol. NS-26, No. 1, p. 316, 1979.

10. L. S. Varnell, W. A. Mohone, E. L. Hull, J. F. Butler, A. S. Wong, SPIE Technical Conference Proceedings, Denver, Colorado, Vol. 2806, 1996.

9. L. M. Bartlett, NASA Goddard Space Flight Center, Greenbelt, Maryland, private communication.

11. L. M. Bartlett, C. M. Stahle, P. Shu, L. M. Barber, S. D. Barthelmy, N. Gehrels, J. F. Krizmanic, P. Kurczyski, D. Palmer, A. Parsons, B. J. Teegarden, and T. Tueller, SPIE Technical Conference Proceedings, Denver, Colorado, Vol. 2859, 1996.

Figures and Captions: 


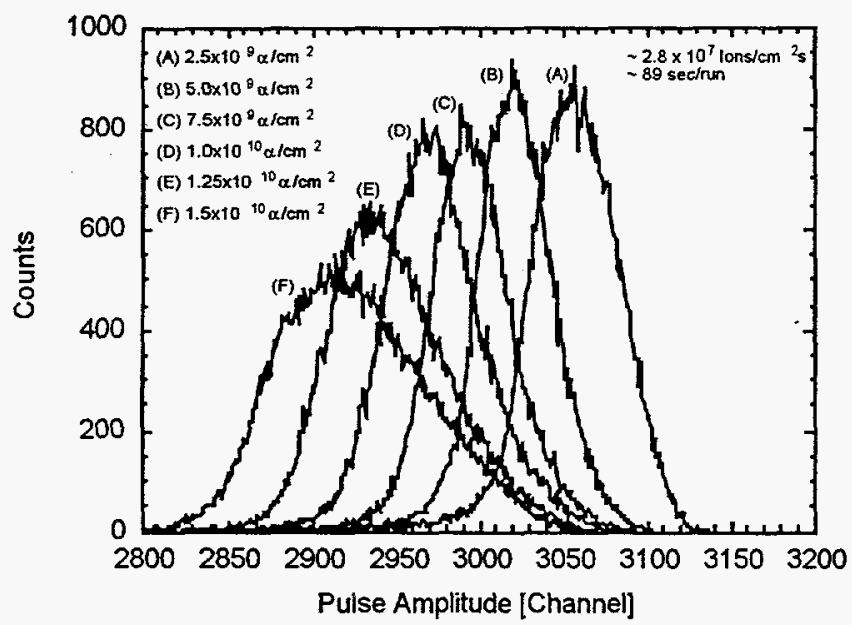

Figure 1. Pulse height spectrum of $5 \mathrm{Mev}$ alpha obtained from a small iradiated area. The alpha flux is $2.8 \times 10^{7} \alpha / \mathrm{cm}^{2}-\mathrm{s}$.

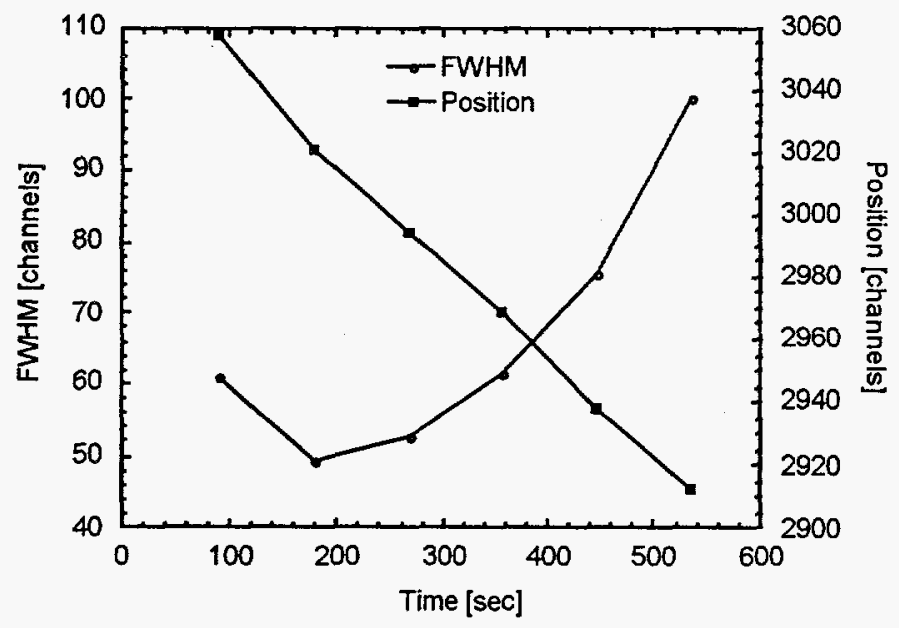

Figure 2. Peak position and full wide at half maximum as a function of exposure time for $\alpha$ irradiated CZT detector. 


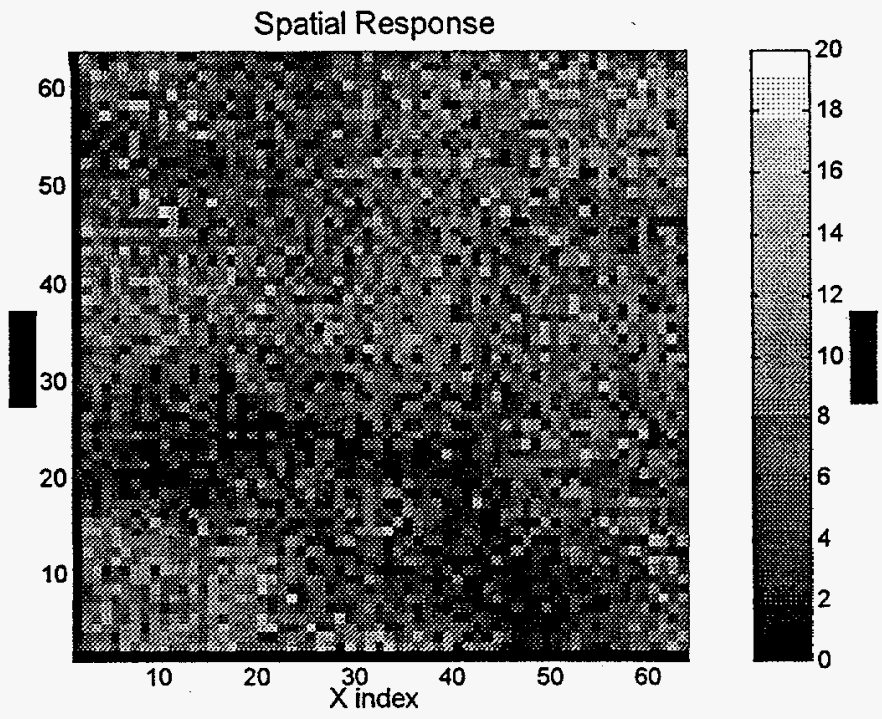

Figure 3. Alpha particle response map of detector surface as measured by deviations in counts in the photopeak channel. Dark areas indicate non-responsive regions. 